\title{
Animal board invited review: genetic possibilities to reduce enteric methane emissions from ruminants
}

\author{
N. K. Pickering ${ }^{1 a}$, V. H. Oddy ${ }^{2}$, J. Basarab ${ }^{3}$, K. Cammack ${ }^{4}$, B. Hayes ${ }^{5,6,7}$, R. S. Hegarty ${ }^{8}$, \\ J. Lassen ${ }^{9}$, J. C. McEwan', S. Miller ${ }^{10,11 b}$, C. S. Pinares-Patiño ${ }^{12 \mathrm{C}}$ and Y. de Haas ${ }^{13 \dagger}$
}

${ }^{1}$ Animal Productivity, AgResearch, Invermay Agricultural Centre, Puddle Alley, PB50034, Mosgiel 9010, New Zealand; ${ }^{2}$ NSW Department of Primary Industries, Beef Industry Centre, University of New England, Armidale NSW 2351, Australia; ${ }^{3}$ Alberta Agriculture and Rural Development, Lacombe Research Centre, 6000 C \& E Trail, Lacombe, AB, Canada T4L 1W1; ${ }^{4}$ Department of Animal Science, University of Wyoming, Laramie, Wyoming 82071, USA; ${ }^{5}$ Biosciences Research Division, Department of Environment and Primary Industries, Bundoora 3083, Victoria, Australia; ${ }^{6}$ Dairy Futures Cooperative Research Centre, Bundoora 3083, Victoria, Australia; ${ }^{7}$ La Trobe University, Bundoora, Victoria, Australia; ${ }^{8}$ University of New England, Armidale NSW, Australia; ${ }^{9}$ Center for Quantitative Genetics and Genomics, Institute of Molecular Biology and Genetics, Aarhus University, Denmark; ${ }^{10}$ Centre for the Genetic Improvement of Livestock, University of Guelph, Guelph, Ontario, Canada; ${ }^{11}$ Livestock Gentec, University of Alberta, Edmonton, Alberta, Canada; ${ }^{12}$ Animal Nutrition \& Health, AgResearch, Grasslands Research Centre, Tennent Drive, PB 11008, Palmerston North, New Zealand; ${ }^{13}$ Animal Breeding and Genomics Centre of Wageningen UR Livestock Research, P.O. Box 135, 6700 AC Wageningen, the Netherlands

(Received 2 July 2014; Accepted 2 March 2015; First published online 9 June 2015)

Measuring and mitigating methane $\left(\mathrm{CH}_{4}\right)$ emissions from livestock is of increasing importance for the environment and for policy making. Potentially, the most sustainable way of reducing enteric $\mathrm{CH}_{4}$ emission from ruminants is through the estimation of genomic breeding values to facilitate genetic selection. There is potential for adopting genetic selection and in the future genomic selection, for reduced $\mathrm{CH}_{4}$ emissions from ruminants. From this review it has been observed that both $\mathrm{CH}_{4}$ emissions and production (g/day) are a heritable and repeatable trait. $\mathrm{CH}_{4}$ emissions are strongly related to feed intake both in the short term (minutes to several hours) and over the medium term (days). When measured over the medium term, $\mathrm{CH}_{4}$ yield $\left(\mathrm{MY}, \mathrm{g} \mathrm{CH}_{4} / \mathrm{kg}\right.$ dry matter intake) is a heritable and repeatable trait albeit with less genetic variation than for $\mathrm{CH}_{4}$ emissions. $\mathrm{CH}_{4}$ emissions of individual animals are moderately repeatable across diets, and across feeding levels, when measured in respiration chambers. Repeatability is lower when short term measurements are used, possibly due to variation in time and amount of feed ingested prior to the measurement. However, while repeated measurements add value; it is preferable the measures be separated by at least 3 to 14 days. This temporal separation of measurements needs to be investigated further. Given the above issue can be resolved, short term (over minutes to hours) measurements of $\mathrm{CH}_{4}$ emissions show promise, especially on systems where animals are fed ad libitum and frequency of meals is high. However, we believe that for short-term measurements to be useful for genetic evaluation, a number (between 3 and 20) of measurements will be required over an extended period of time (weeks to months). There are opportunities for using short-term measurements in standardised feeding situations such as breath 'sniffers' attached to milking parlours or total mixed ration feeding bins, to measure $\mathrm{CH}_{4}$. Genomic selection has the potential to reduce both $\mathrm{CH}_{4}$ emissions and MY, but measurements on thousands of individuals will be required. This includes the need for combined resources across countries in an international effort, emphasising the need to acknowledge the impact of animal and production systems on measurement of the $\mathrm{CH}_{4}$ trait during design of experiments.

Keywords: genetics, greenhouse gases, enteric methane, ruminants

\footnotetext{
a Present address: Focus Genetics, PO Box 12075, Ahuriri, Napier 4144, New Zealand

b Present address: Animal Productivity, AgResearch, Invermay Agricultural Centre, Puddle Alley, PB50034, Mosgiel 9010, New Zealand

c Present address: CSIRO Integrated Agricultural Systems at Black Mountain Canberra, Australia

${ }^{\dagger}$ E-mail: Yvette.deHaas@wur.nl
}

\section{Implication}

Measuring and mitigating methane $\left(\mathrm{CH}_{4}\right)$ emissions from livestock is of increasing importance for the environment and for policy making. Potentially, the most sustainable way of reducing enteric $\mathrm{CH}_{4}$ emission from ruminants is through the estimation of genomic breeding values to facilitate genetic selection. Enteric $\mathrm{CH}_{4}$ emissions are difficult and expensive to measure, thus genomic prediction could provide significant, 
long-term economic benefits. Implementation will require global collaboration to define a suitable measure and many thousands of records to ensure valid and accurate evaluations.

\section{Introduction}

Climate change is of growing international concern and it is well established that the release of greenhouse gases (GHG) is the driving factor (IPCC, 2006). Globally, livestock farming contributes $\sim 9 \%$ to $11 \%$ of total anthropogenic GHG emissions (Smith et al., 2007; Tubiello et al., 2013). Of the various GHG, methane $\left(\mathrm{CH}_{4}\right)$ is the most important agricultural contributor, with a global warming potential 25 times that of carbon dioxide $\left(\mathrm{CO}_{2}\right)$ (Forster et al., 2007).

Globally, in the year 2010, GHG emissions from the agriculture sector accounted for $4.6 \mathrm{GtCO}_{2}$ eq, of which enteric fermentation (emissions of $\mathrm{CH}_{4}$ from ruminant animals) contributed $2 \mathrm{GtCO}_{2}$ eq (Tubiello et al., 2013), with an annual increase of $0.95 \%$ between 1961 and 2010. Non-dairy cattle were the single largest source of enteric $\mathrm{CH}_{4}$, followed by dairy cattle, buffaloes, sheep and goats (FAOSTAT, 2013). Enteric $\mathrm{CH}_{4}$ emissions from ruminant livestock (cattle, sheep and goats) account for $2 \%$ to $12 \%$ of gross energy intake (Blaxter, 1962; Johnson and Johnson, 1995). Although $\mathrm{CH}_{4}$ production is an energy loss to ruminants, it can also be considered a small price to pay for their adaptation to digest cellulose-based feeds. Sources of systematic variation in $\mathrm{CH}_{4}$ production by an individual animal include: total feed intake, the nutrient composition of the feed eaten, the proportion and rate of fermentation of that feed in the rumen, feeding frequency (for recent reviews see Hristov et al., 2013a and 2013b), rumen volume and rate of passage of digesta from the rumen (Goopy et al., 2014), physiological state of the animal and variation between individual animals including that between sire families (Pinares-Patiño et al., 2013a).

Production of $\mathrm{CH}_{4}$ (and other GHGs) per unit of animal product (e.g. milk, meat) has declined over the past 50 years in most ruminant livestock industries in developed countries due to ongoing improvements in animal productivity. For example, the carbon footprint, in terms of $\mathrm{CO}_{2} \mathrm{eq} / \mathrm{kg}$ of milk produced, of the US dairy industry in 2007 was $37 \%$ of that in 1944 (Capper et al., 2009). Productivity improvements included a change of breed type of the dairy cow (to Holstein), improved genetics within the Holstein breed and a shift from a forage based to total mixed ration feeding system (see Capper et al., 2009). Similarly, analysis of the carbon footprint of total US beef production indicates a reduction of $\mathrm{CO}_{2}$ eq of $16 \%$ per $\mathrm{kg}$ of beef produced in 2007 compared with 1977 (Capper, 2011), due to a reduction in total feedstuff used, changed industry structure, improved nutritional management and improved herd genetics.

Most of the mitigation potential in the livestock sector is found in the developing countries. However, for these countries, it is important to combine development and mitigation strategies, like adapted selection programmes and feeding strategies, as a lot can still be achieved in developing countries by increasing lifetime production of animals (Gerber et al., 2013).

The extent to which genetic improvement can contribute to improvement in individual animal milk production and consequent impacts on GHG emissions has been highlighted by Wall et al. (2010). They described how systematic improvement in environmental outcomes has resulted from productivity improvements and discussed how direct and indirect measures of emissions can be incorporated into breeding objectives to reduce emissions.

There are many potential methods to reduce enteric $\mathrm{CH}_{4}$ emissions per head and thereby intensity of $\mathrm{CH}_{4}$ production per unit product. These include: changing feed type (e.g. from pasture to concentrate feed or to new pasture varieties); use of supplements that reduce $\mathrm{CH}_{4}$ emissions (fats, oils, plant extracts and nitrate); improving productivity through management change including use of growth enhancers and improved genetics; immunisation against methanogens and selective breeding of animals with low $\mathrm{CH}_{4}$ emissions, through either reduced feed intake per product or reduced $\mathrm{CH}_{4}$ production per feed consumed, without compromising production characteristics (Martin et al., 2010; Wall et al., 2010). The aim of this review is to provide an overview of possibilities and some of the remaining issues that need to be addressed to realise these possibilities to genetically reduce enteric $\mathrm{CH}_{4}$ emissions by livestock.

\section{Quantifying enteric $\mathrm{CH}_{4}$ emission}

There are three levels in which a $\mathrm{CH}_{4}$ trait can be defined; first, the farm system level which uses information on the number of animals present within a system boundary with a related estimate of $\mathrm{CH}_{4}$ emissions per head, calculated for example from the Intergovernmental Panel on Climate Change (2006) Tier 2 calculations. These calculations have embedded within them a number of assumptions about the factors which affect $\mathrm{CH}_{4}$ emission per head, that is feed intake, feed quality and $\mathrm{CH}_{4}$ yield. Second, the animal production level which uses information about productivity per head that is milk yield or $\mathrm{kg}$ carcass weight, from individual animals to give us $\mathrm{CH}_{4}$ intensity $\left(\mathrm{g} \mathrm{CH}_{4} / \mathrm{kg}\right.$ product). Finally, at the animal level, individual $\mathrm{CH}_{4}$ emissions and feed intake measurements to enable genetic progress on $\mathrm{CH}_{4}$ yield ( $\mathrm{MY} ; \mathrm{g} \mathrm{CH} / \mathrm{kg}$ dry matter intake (DMI)), or residual feed intake (RFl; MJ/day), which is the difference between net energy intake and calculated energy requirements for maintenance as a function of live weight and for fat and protein corrected milk yield.

\section{Methodologies for measurement of $\mathrm{CH}_{4}$ from ruminants}

The respiratory chamber (RC) system is often viewed as a 'gold standard' for emission measurement. There is little question $\mathrm{RC}$ measurements accurately quantify $\mathrm{CH}_{4}$ output over the 1 to 3-day measurement period typically used, and they achieve this by frequently measuring emissions. 
The variability in emission rate resulting from eructation events, animal position and feed intake that occur in $24 \mathrm{~h}$, are typically damped within the large chamber volume. Feeding in RCs can also cause a reduction in feed intake (relative to pre-chamber intakes) and completely eliminates diet selection and feeding pattern which has strong genetic control and may well be a means by which animal genetics moderates emission in the grazing environment (Hegarty, 2004). The RCs rarely monitor $\mathrm{CH}_{4}$ outflow on a second by second basis, the chambers used to estimate $\mathrm{CH}_{4}$ parameters do so by measuring volume of air flow coupled with intermittent sampling (at 3 to $13 \mathrm{~min}$ ) of gas for determination of $\mathrm{CH}_{4}$ concentrations. This means that hourly measurements described here consist of averages of 4 to 20 measurements each taken over a few seconds (albeit averaged via dilution in a large volume that is the chamber). As shown by PinaresPatiño et al. (2013a) a 1 to 3-day collection only poorly describes the $\mathrm{CH}_{4}$ phenotype of an animal over a year or a lifetime and could benefit from repeated measurements. In reality, $\mathrm{CH}_{4}$ is largely emitted intermittently via brief eructations or burps lasting only seconds, albeit with a basal level of emission.

The sulfur hexafluoride $\left(\mathrm{SF}_{6}\right)$ technique is one tool that offers field measurement over a longer time, but requires insertion of rumen boluses, daily animal handling and laboratory measurement of gases (McGinn et al., 2006). Moreover, the sampling procedures provide an average $\mathrm{CH}_{4}$ output for periods of typically $24 \mathrm{~h}$, but can be repeated over periods of 5 to 10 days, or until the rate of release of $\mathrm{SF}_{6}$ from the permeation tube is no longer stable. While repeatability of daily $\mathrm{CH}_{4}$ production is being improved as the methodology is refined (Deighton et al., 2013), SF ${ }_{6}$ remains a very demanding method to get accurate emission measures over multiple days in individual animals.

Other systems that measure (or estimate) emissions over multiple short periods per day with minimal operator input have been developed. These include measuring all emissions from animals in short-term confinement; that is, Portable Accumulation Chambers (PAC; Goopy et al., 2011), monitoring eructations in feeding stations (Negussie et al., 2012) or voluntary milking systems for dairy cattle (Garnsworthy et al., 2012; Lassen et al., 2012), or Greenfeed monitors (GEM). A hand-held laser has been used to estimate $\mathrm{CH}_{4}$ flux indirectly from dairy cattle (Chagunda et al., 2013). All of these methods, except PAC and GEM, measure concentrations, and assume that they have a constant recovery or little drift, and are therefore accurately reflecting gross flux from the animal over the recorded period. Similarly, all short-term estimates also assume that there is a high genetic correlation with longer term measurements and that this is essentially independent of when the animals are recorded. Average $\mathrm{CH}_{4}$ emissions in various units, heritability estimates, where known, and various repeatability estimates for example across days, across periods and across rounds are shown in Supplementary Table S1 for cattle and in Supplementary Table S2 for sheep. There are a wide array of variables including; system (RC, $\mathrm{SF}_{6}$, laser, GEM or PACs), diet (composition and particle size), feeding level (ad libitum or at a proportion of maintenance) and experimental period. Despite this, gross $\mathrm{CH}_{4}$ production and repeatability estimates are not so different. However, MY is variable with a noticeable difference between studies where animals are fed at a proportion of maintenance versus those that are fed ad libitum. Those fed at maintenance are theoretically estimating $\mathrm{CH}_{4}$ emission per live weight as much as $\mathrm{CH}_{4}$ emission per unit intake; $\mathrm{CH}_{4}$ emissions increases with live weight, and thus the ratio measure could be similar across time points in maintenance fed studies.

In summary, daily enteric emission is principally constrained by the quantity and fermentability of the feed consumed; but an understanding of within-day and between-day variances is required to ensure the emission data collected reflects the long-term $\mathrm{CH}_{4}$ phenotype of a ruminant. When collecting records for selective breeding, it will often be a choice between accuracy of the phenotype and number of records. In the case of gross $\mathrm{CH}_{4}$ production the most accurate method would be the RC method, but in order to generate enough data to do selective breeding and make recordings in practice, this method has limitations. Alternately, compared to RC, spot breath samples taken during milking in dairy cattle might be less accurate phenotypes for selective breeding, but can generate a large number of individual animal records. A genetic and environmental correlation structure between these methods together with $1 \mathrm{~h} \mathrm{RC}$ methods, $\mathrm{SF}_{6}$ and other methods is needed and would allow merging of data to generate enough data for use in selective breeding.

\section{Implications for measurement}

Three messages on repeatability emerge from Supplementary Table $\mathrm{S} 1$ and $\mathrm{S} 2$. The repeatability of daily $\mathrm{CH}_{4}$ emissions is highest between $\mathrm{RC}$ measures made on consecutive days, but diminishes as time between measures increases. Repeatability of $\mathrm{CH}_{4}$ emission is lower for short term measurement systems (e.g. PACs) relative to RC system. Consequently, more measures will be required from shortterm measurement methods to capture variation within a day, but multiple samples across many days offers additional information about the robustness of the emissions phenotype that is not normally obtained by RC studies made only over 1 to 3 days. So far, we have not been able to source sufficient structured data from these methods and protocols to develop a common procedure for measurement of rate of $\mathrm{CH}_{4}$ emissions capable of being used for genetic selection.

McEwan et al. (2012) assessed the usefullness of multiple $1 \mathrm{~h}$ measures of emissions compared to $22 \mathrm{~h} \mathrm{RC}$ measures using 684 sheep and found a high genetic correlation between $24 \mathrm{~h}$ emission measure and a $1 \mathrm{~h}$ emission measure ( 0.89 for $\mathrm{g} \mathrm{CH}_{4} /$ day and 0.76 for MY). They estimated there is little difference in estimates of $\mathrm{CH}_{4}$ emissions and $\mathrm{MY}$ by measuring animals twice in a RC, 14 days apart, or by measuring an animal four times for $1 \mathrm{~h}, 14$ days apart. Such assessments indicate that using a range of measurement technologies is possible, but the intensity of sampling 
required and number of animals needing to be measured will be different for each system used.

It has been calculated that $3 \times 1 \mathrm{~h}$ PAC measurements will be as useful at describing $\mathrm{CH}_{4}$ production rate as one $\mathrm{RC}$ measure for 1 day (Bickell et al., 2011). Defining this comparability is a key requirement for developing measurement protocols of equivalent power to use in genetic selection.

Pinares-Patiño et al. (2011) showed that groups of animals selected to be high or low MY when consuming $2.2 \times$ maintenance lucerne pellets retained their ranking when fed lucerne and concentrate pellets. Subsequently they (C.S. Pinares-Patiño personal communication) demonstrated that with five different diets the groups remained different in MY, although individuals in the groups sometimes re-ranked (Table 1). Similar results were obtained by Michal et al. (2013) from growing beef heifers fed three different diets. This suggests that using a standard diet to assess rank of animals for MY is useful and the rankings are likely to hold across a range of production diets. The data also suggest that the differences in MY between animals in high and low MY groups (and therefore individuals) are greater when they are eating a more digestible diet. This suggests that the discriminatory power of a phenotype test could be expanded by feeding a mixed ration of forage and concentrate, although this requires testing with more animals.

\section{Breeding to reduce $\mathrm{CH}_{4}$ emissions from livestock}

Genetic selection provides a reliable route towards permanent and cumulative reductions in quantitative traits such as enteric $\mathrm{CH}_{4}$ emissions.

To justify investment of effort and money in developing protocols for measurement of emissions to support genetic improvement in a $\mathrm{CH}_{4}$ trait, it is worth summarising evidence supportive of this breeding strategy (Lassey et al., 1997). Genetic diversity in a range of digestive parameters likely to be associated with enteric $\mathrm{CH}_{4}$ production was apparent when reviewed in 2002 (Hegarty, 2004). The prospect for

Table 1 Consistency of response of sheep selected on basis of methane yield ( $\mathrm{g} \mathrm{CH}_{4} / \mathrm{kgDMI}$ ) across time and a range of diets (C.S. PinaresPatiño personal communication)

\begin{tabular}{|c|c|c|c|c|}
\hline \multirow[b]{2}{*}{$\begin{array}{l}\text { Time of } \\
\text { measurement }\end{array}$} & \multirow[b]{2}{*}{$\begin{array}{l}\text { Diet (fed at } \\
1.3 \text { to } 1.6 \mathrm{M} \text { ) }\end{array}$} & \multicolumn{3}{|c|}{$\mathrm{CH}_{4}$ yield (g/kg DMI) } \\
\hline & & $\begin{array}{c}\text { Low } \\
\text { group } \\
(n=10)\end{array}$ & $\begin{array}{l}\text { High } \\
\text { group } \\
(n=10)\end{array}$ & $\begin{array}{l}\% \text { Difference } \\
\text { between high } \\
\text { and low } \\
\text { group }\end{array}$ \\
\hline August 2008 & Grass silage & 17.8 & 19.2 & 7.8 \\
\hline May 2009 & Fresh grass & 22.5 & 24.4 & 8.4 \\
\hline June 2009 & $\begin{array}{c}60 \% \text { Forage, } 40 \% \\
\text { concentrate } \mathrm{P}\end{array}$ & 18.6 & 23.6 & 27.4 \\
\hline January 2010 & Fresh grass & 22.2 & 25.3 & 13.8 \\
\hline March 2010 & $\begin{array}{c}40 \% \text { Forage } 60 \% \\
\text { concentrate } P\end{array}$ & 8.9 & 12.8 & 43.8 \\
\hline
\end{tabular}

selection for a $\mathrm{CH}_{4}$ trait was initially investigated by multiple groups; some identified variation in $\mathrm{CH}_{4}$ traits amenable to animal selection (Robinson et al., 2010) and some did not (Münger and Kreuzer, 2008). More recent research in 530 beef animals (Donoghue et al., 2013) and 1225 sheep (Pinares-Patiño et al., 2011 and 2013a) is increasingly supportive of $\mathrm{CH}_{4}$ traits being heritable with improvement by direct selection achievable.

Based on records of 1277 pedigreed sheep, estimated heritability and repeatability of $\mathrm{CH}_{4}$ across days, rounds and years, using the total $24 \mathrm{~h}$ measurement were $0.29 \pm 0.05$ and $0.13 \pm 0.03$ for gross $\mathrm{CH}_{4}$ production ( $\mathrm{g} /$ day), and MY (g / kg DMl), respectively (Pinares-Patiño et al., 2013a). There were high repeatabilities across consecutive days. Across rounds and across years the repeatability estimates were lower than for consecutive days, but, relatively stable. Estimation of genetic and phenotypic correlations with some of the main New Zealand production traits; weaning weight at 3 months, live weight at 8 months, fleece weight at 12 months (FW12), eye muscle depth and dag score (accumulation of faeces on the perineum region) at 3 or 8 months of age show that correlations with MY are low or close to zero, the only exception was FW12. The negative genetic and phenotypic correlations of FW12 with MY $(-0.32 \pm 0.11$ and $-0.08 \pm 0.03$, respectively) imply that selecting for increased hogget fleece weight would in part result in lower $\mathrm{CH}_{4}$ yield.

Results from Donoghue et al. (2013) on Australian Angus beef cattle showed very similar heritabilities. Based on 530 pedigreed cattle, fed at a proportion of maintenance $(1.2 \times)$, heritability estimates for gross $\mathrm{CH}_{4}$ production (L/day), and MY (L/kg DMI) were $0.40 \pm 0.11$ and $0.19 \pm 0.10$, respectively. Genetic and phenotypic correlations of gross $\mathrm{CH}_{4}$ production with eye muscle area were $0.17 \pm 0.29$ and $-0.01 \pm 0.05$, respectively. With MY, the genetic and phenotypic correlations were $-0.02 \pm 0.30$ and $-0.03 \pm 0.05$, respectively.

Both studies are based on $24 \mathrm{~h} \mathrm{RC}$ measurement with known feed intake. However, the cost of routinely measuring $\mathrm{CH}_{4}$ emissions using $\mathrm{RC}$ is thought to be prohibitive for a testing programme using industry animals. Therefore, protocols for measuring or estimating $\mathrm{CH}_{4}$ production and feed intake are required that need less time and cost. It has to be kept in mind that phenotype recording of feed intake or DMI is most limiting in commercial condition and generally only recorded on experimental farms.

In the longer term, it may be possible to incorporate genomic information to estimate genomic breeding values (GEBVs) for $\mathrm{CH}_{4}$ emissions into breeding schemes (Meuwissen et al., 2013). For GEBVs to be implemented, a reference population of several thousand genotyped industry relevant animals, with the $\mathrm{CH}_{4}$ phenotype measured, is required to provide initial estimates of the contribution of each genomic region to the expression of the phenotype under investigation (Calus et al., 2013). Similarly, selection on GEBVs for correlated indicator traits can be used where it is impractical to directly measure $\mathrm{CH}_{4}$ on enough animals to establish a reference population. Finally, there must be an 
economic (and/or social) incentive to breed animals with the trait which is incorporated in the selection objective, so that the $\mathrm{CH}_{4}$ trait receives the appropriate weighting in any breeding programme.

There is already on-going improvement in emissions intensity that is $\mathrm{CH}_{4}$ emissions per unit product, arising from genetic selection for current production traits (Capper et al., 2009; Wall et al., 2010; Hayes et al., 2013). One could therefore argue that further research investment into this area (i.e. selection for reduced intensity of $\mathrm{CH}_{4}$ emissions) is not necessary. However, selection solely on productivity traits such as live weight gain and/or milk production will increase feed intake and $\mathrm{CH}_{4}$ emissions per animal and hence total $\mathrm{CH}_{4}$ emissions unless a physical or economic constraint is imposed on total emissions. For dairy products, there is a market constraint on total production which has resulted in an increase in productivity per cow and a decrease in number of animals. This may suit some industries, but poses the question 'is it possible to increase productivity and reduce $\mathrm{CH}_{4}$ emissions per animal at the same time?' This could be achieved by reducing $\mathrm{MY}$ that is $\mathrm{CH}_{4}$ per unit feed consumed, and/or decreasing DMI provided that there is no concomitant reduction in productivity or increase in feed consumption. Selection on MY provides options to either reduce emissions while holding net enterprise feed consumption constant, or alternatively, allowing intake to increase supporting a production boost per animal without raising total emissions. Early results from a number of studies around the world, suggest that MY is both a heritable and repeatable trait (e.g. Pinares-Patiño et al., 2013a). However, the means by which the host influences fermentation in the gut to affect $\mathrm{CH}_{4}$ production is still largely unknown. The extent to which genetic selection can be used to reduce MY is also not known. The methods by which $\mathrm{CH}_{4}$ emissions of individual animals can be measured are an important factor because the method used to measure the $\mathrm{CH}_{4}$ trait will also influence the resulting genetic parameters and is therefore an integral part of the selection programme. Besides, caution should be taken for ratio traits, as the genetic parameters may not truly represent the trait under consideration, because there is always extra variability of the denominator trait.

It is also important to remember that fertility and longevity have a huge aspect in the overall environmental impact of livestock, and therefore improved fertility and longevity through breeding and management will also be important mitigation strategies (Cottle et al., 2011).

\section{Understanding animal variation in $\mathrm{CH}_{4}$ production over time}

\section{Sources and transfer of $\mathrm{CH}_{4}$ within the ruminant}

While $\mathrm{CH}_{4}$ is produced in both the reticulo-rumen and the hindgut, some transfer within the animal occurs before the $\mathrm{CH}_{4}$ is emitted. For example, in ewes eating lucerne, $97.5 \%$ of $\mathrm{CH}_{4}$ emission was voided via the oesophagus and lungs and only $2.5 \%$ via flatus, despite $23 \%$ of $\mathrm{CH}_{4}$ production occurring in the lower gut, presumably because of absorption of hindgut $\mathrm{CH}_{4}$ into the blood (Murray et al., 1976). Cattle studies have shown the proportion of $\mathrm{CH}_{4}$ derived from the hindgut increases with feeding level (Hofmeyr et al., 1984). Most of the $\mathrm{CH}_{4}$ leaving the rumen in oesophageal eructation is subsequently drawn into the lungs and then emitted in exhaled breath; although some rumen produced $\mathrm{CH}_{4}$ is also absorbed into the blood and diffuses into the lungs without passing up the oesophagus. This has been confirmed by dosing and radiotracer studies (Dougherty et al., 1964; Heywood and Wood, 1985). The fraction of $\mathrm{CH}_{4}$ absorbed into the bloodstream from the gastrointestinal tract decreases as volume of eructated gas increases; also when an animal is not ruminating (Hoernicke et al., 1965); and also after feeding (Hoernicke et al., 1965). Studies with tracheotomised cattle have revealed that before feeding, $25 \%$ to $94 \%$ of the total $\mathrm{CH}_{4}$ emission (flatus not included) was by exhalation, whereas after feeding exhalation is reduced to $9 \%$ to $43 \%$ of emissions.

Cattle eructate every 40 to $90 \mathrm{~s}$ and take between 25 and 40 breaths per minute (Mortola and Lanthier, 2005), although the frequency of eructation peaks is reduced when drinking (Hegarty, 2013). As breathing frequency in cattle oscillates within a day and varies largely between animals (Piccione et al., 2004), differences in gas excretion mechanisms (eructation, tracheal inhalation, exhalation and expiration) might differ considerably among individual animals.

While the proportion of $\mathrm{CH}_{4}$ entering the lungs by absorption or by inhalation varies, the important value is the absolute quantity and constancy of $\mathrm{CH}_{4}$ leaving the mouth and nose. Large oscillations in $\mathrm{CH}_{4}$ release rate (but not necessarily methanogenesis rate) are observed during $\mathrm{CH}_{4}$ measurements. Animal position and activity is known to affect pooling of gas in the rumen (McCauley and Dziuk, 1965), and pooling of gas in the rumen may be part of the reason that variable short term $\mathrm{CH}_{4}$ production rates are seen during $\mathrm{RC}$ studies even from animals fed at $2 \mathrm{~h}$ intervals (e.g. Figure 1a: Nolan et al., 2010; Figure 1b: Mathers and Walters, 1982). Enteric $\mathrm{CH}_{4}$ production rate varies widely over $2 \mathrm{~h}$ intervals (Figure $1 \mathrm{~b}$ ), potentially contributing to a highly variable estimate of emission rate if measurements are short term. Mathers and Walters (1982) acknowledged 'violent shortterm variations were evident in the plots of the observations', so emission rates were averaged, over various periods, to generate smoother emission profiles. Poor in-chamber mixing of air can cause similar variability in emission rates assessed over the short term (Gardiner and Coleman, 2013).

\section{Diurnal and longer term emission cycles}

In the grazing environment, ruminants are considered to ingest most of their feed in morning and late-afternoon feeding sessions (see Gregorini, 2012 for recent review). Emulation of this pattern in RCs (Robinson, 2009) shows a biphasic diurnal $\mathrm{CH}_{4}$ emission pattern, consistent with timing of feed intake, but there was no difference in either total daily emission or MY when feed was provided in a single meal or as four equal meals in the morning and four equal meals in the afternoon. Murray et al. (2001) found a 
(a)

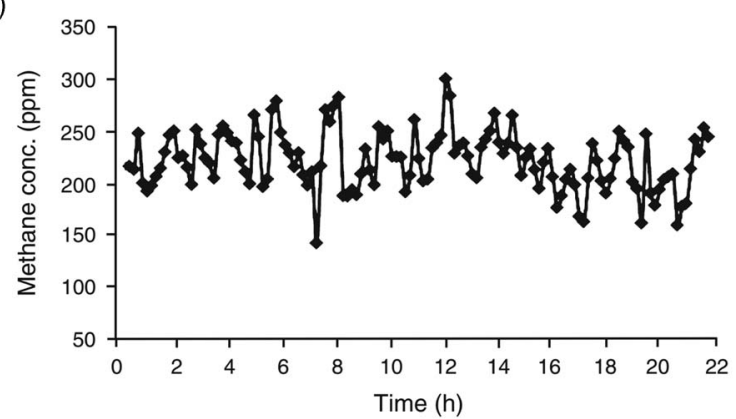

(b)

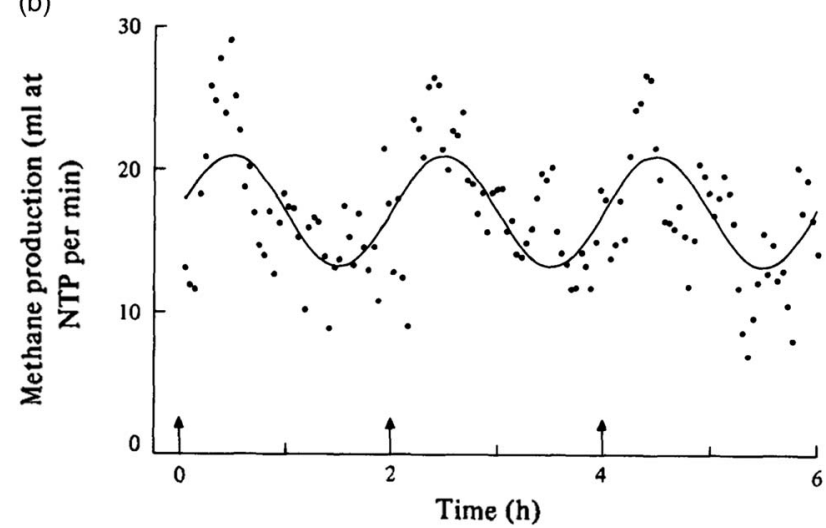

Figure 1 Time course of (a) methane concentrations (ppm) in respiration chambers (reproduced Nolan et al., 2010, figure 1a), and (b) methane production $(\mathrm{ml} / \mathrm{min}$ ) (reproduced from Mathers and Walters, 1982, figure 2a), of sheep fed using an automated feeder at 2-h intervals.

similar pattern of biphasic emissions in grazing sheep using a polytunnel.

A number of studies offer evidence of repeatability of emissions over prolonged periods, but the repeatability is confounded by the variations in pasture cover that occur with changes in season (Knight et al., 2008; Münger and Kreuzer, 2008), so do not reflect innate repeatability of emission by the animal as would occur if the same diet was fed for a prolonged period.

Recent sheep genetics research provides evidence of repeatability over extended time intervals when a consistent diet is fed (Pinares-Patiño et al., 2013a) and confounding with changes in feed composition do not occur.

\section{Indirect selection to reduce emissions}

Measuring $\mathrm{CH}_{4}$ emissions directly from animals is difficult and thereby hinders direct selection on reduced $\mathrm{CH}_{4}$ emission. However, improvements can be made through selection on associated traits (e.g. RFI), volatile fatty acids (VFA), milk composition or through selection on $\mathrm{CH}_{4}$ predicted from feed intake and diet composition.

\section{VFAs}

The rumen microbial population converts the host ingested food in the rumen into $\mathrm{CO}_{2}$, hydrogen $\left(\mathrm{H}_{2}\right)$, VFA and microbial cells. The host absorbs the VFA across the rumen for its own use and rumen methanogens act on the $\mathrm{H}_{2}$ to produce $\mathrm{CH}_{4}$. High $\mathrm{H}_{2}$ concentrations are thought to stimulate methanogenesis while suppressing production of acetate and VFA in general, while low $\mathrm{H}_{2}$ concentrations will stimulate VFA production, especially acetogenesis but suppress methanogenesis. VFA are thus a potential proxy for estimating $\mathrm{CH}_{4}$ emissions. For sheep, Pinares-Patiño et al. (2013b) measured 1081 animals for VFA soon after exit from $\mathrm{RCs}$. There were high genetic correlations $(>0.78)$ of MY with $\log _{\mathrm{e}}$ mM VFA concentrations. Genetic correlations are lower, but still moderate, when VFAs were expressed as molar \%.

For cattle, Herd et al. (2013) measured VFAs and other parameters from 532 young Angus bulls and heifers soon after exit from the RCs (at least $12 \mathrm{~h}$ post feed consumption). Pearson correlation coefficients with $\mathrm{CH}_{4}$ production (L/day), MY (L/kg DMI) and $\mathrm{CH}_{4}$ intensity ( $\mathrm{L} / \mathrm{kg}$ live weight gain) were estimated. There were correlations of 0.40 with $\mathrm{MY}$ and $\mathrm{CH}_{4}$ emission intensity, but correlations with gross $\mathrm{CH}_{4}$ production were almost zero. Other studies (Robinson et al., 2010), suggest that VFA concentration has limited utility in predicting $\mathrm{CH}_{4}$ emissions, although VFA production rate may be useful (McPhee and Hegarty, 2008). This contrasting evidence indicates considerable work is still required before the utility of VFA as an indicator of $\mathrm{CH}_{4}$ emissions can be realised.

\section{Prediction form mid-infrared spectra of milk samples}

Mid-infrared spectra (MIR) of milk samples are generated routinely by national and commercial laboratories for prediction of milk composition during milk recording. Therefore, any approach that utilizes this information can immediately be implemented but also applied retrospectively to already analyzed samples with the spectral data stored. In vivo experiments performed using the $\mathrm{SF}_{6}$ method showed that it is possible to estimate $\mathrm{CH}_{4}$ emissions of lactating dairy cows from MIR spectra of milk samples (Dehareng et al., 2012). A possible delay between a variation in $\mathrm{CH}_{4}$ emission and an onset in milk response was mentioned by these authors. These preliminary results suggest the possibility to predict individual $\mathrm{CH}_{4}$ emissions, allowing at least inventory type of assessments at a farm level or at a regional scale. With more collaboration and additional data, an improved equation could be generated. Predictions could then become robust enough to use MIR spectra to identify individually low- $\mathrm{CH}_{4}$-emitting cows and to develop selection and management tools to reduce $\mathrm{CH}_{4}$ emissions.

\section{Prediction from feed intake and diet composition}

The objective of a Dutch study was to establish phenotypic and genetic variation in predicted $\mathrm{CH}_{4}$ output, and to determine the potential that genetic selection has in reducing $\mathrm{CH}_{4}$ emissions in dairy cattle (de Haas et al., 2011). Records on daily feed intake, weekly live weights and weekly milk productions were available from 588 heifers. Along with RFI, predicted $\mathrm{CH}_{4}$ emissions (PME, g/day) and fat and proteincorrected milk production (FPCM, kg/day) were estimated. The estimated heritabilities for PME and RFI were 0.35 and 0.40 , respectively. The positive phenotypic and genetic 
correlations between RFI and PME indicated that cows with lower RFI have lower PME as well (estimates ranging from 0.18 to 0.84 in different periods of the lactation). However, the association between these indicator traits and true $\mathrm{CH}_{4}$ output is unknown. It is still possible to decrease $\mathrm{CH}_{4}$ production of a cow by selecting more efficient (low RFI) cows, and the genetic variation suggests that reductions in the order of $11 \%$ to $26 \%$ in 10 years are theoretically possible, and in a genomic selection programme even higher. However, as stated previously, it is essential to ensure selection on production does not increase feed intake and $\mathrm{CH}_{4}$ emissions per animal and hence total $\mathrm{CH}_{4}$ emissions.

\section{$\mathrm{CH}_{4}$ in a genomic selection programme}

$\mathrm{CH}_{4}$ emissions (as $\mathrm{g} \mathrm{CH}_{4} /$ day or MY) certainly fit the description of hard to measure traits. Methods currently available are expensive and time consuming (RCs and $\mathrm{SF}_{6}$ ) and subject animals to artificial environments. Those that measure animals in production situations (pasture, feedlot or dairy feeding station) sample $\mathrm{CH}_{4}$ for only a part of a day and require repeat measurements (PACs, Sniffers or GEM) and in some cases calculation back to known standard procedures. Those methods of estimating $\mathrm{CH}_{4}$ emissions that rely on computation of differences between feeding standards and production account for only part of the potential variation in $\mathrm{CH}_{4}$ emissions between animals.

Genomic selection opens the possibility to efficiently select for hard to measure traits. It is progressively being used to increase rate of genetic progress for production traits that are measured late in life (e.g. meat yield and quality), expensive to measure (e.g. RFI) and are sex linked (e.g. milk production and quality). In the dairy and increasingly in the beef and sheep industries leading sires are routinely genotyped and GEBVs are used in making selection decisions. It is doubtful that adding the cost of genotyping onto a population in which $\mathrm{CH}_{4}$ is measured would be cost effective, but by using industry animals which have measured production traits and have been genotyped it would be possible to estimate GEBVs for $\mathrm{CH}_{4}$ emissions. This is predicated on having a large reference population, where $\mathrm{CH}_{4}$ emission levels can be measured cheaply and genome wide DNA marker effects have been estimated, to establish the prediction equation for marker effects.

The key question is how large does this reference population have to be, that is, how many animals need to be measured for $\mathrm{CH}_{4}$ and genotyped with the genome wide marker panels? Daetwyler et al. (2008), Goddard (2008) and Hayes et al. (2009) have all derived deterministic formula to estimate the accuracy of GEBV that could be achieved given the size of the reference population, the heritability of the trait and the effective population size. The accuracy of genomic selection for selection candidates (i.e. animals with a genotype, but no measured phenotype) with increasing size of reference population is shown in Figure 2. This was derived from the heritability of MY of 0.13 (Pinares-Patiño et al., 2013a) and an effective population

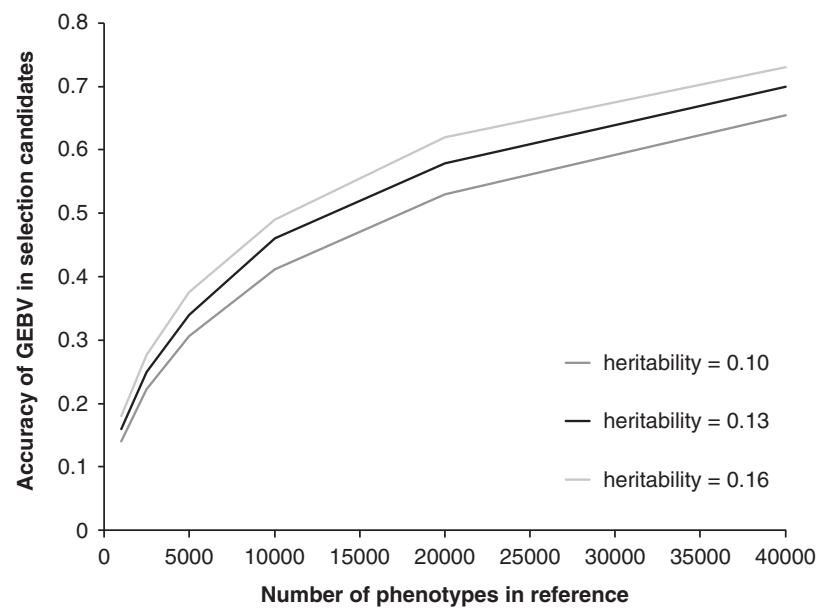

Figure 2 Accuracy of genomic estimated breeding values (GEBV) for methane yield (MY) in selection candidates as a function of heritability of the trait and number of animals with phenotypes in the reference population. Estimates of heritability of MY in sheep were obtained from Pinares-Patiño et al. (2013a).

size of 150 using the procedure described by Hayes et al. (2009). This graph assumes perfect linkage disequilibrium between the single nucleotide polymorphisms (SNP) and quantitative trait loci, which is unlikely for the current available chips and thus the graph will asymptote to the proportion of variance explained. For example, for dairy cattle using the Bovine $50 \mathrm{~K}$ SNP chip this would be $90 \%$. The estimates also assume unrelated individuals, if individuals were related, particularly the selection candidates and the reference population, the accuracy would be greater, as this is effectively reducing the effective population size. Finally, if the individuals in the reference population were progeny tested, this would make the 'heritability' of the trait much higher and thus would require fewer animals genotyped to achieve the same accuracy, however, the total number of animals measured for $\mathrm{CH}_{4}$ to achieve the same accuracy would stay the same.

Because MY is a new trait, it would be anticipated that even low initial accuracy will be useful to industry. As further animals are phenotyped the GEBVs would become increasingly useful. It remains to be determined if MY is independent of other (production) traits. If it is, then adding information from the GEBVs for MY into a selection index is relatively straightforward.

The number of animals with phenotypes in the reference population required to obtain GEBVs of high accuracy for MY is large and almost certainly exceed the resources available in any one country. To overcome these limitations an international effort is required to bring together data on production, feed intake and $\mathrm{CH}_{4}$ emissions of ruminants.

\section{Potential reduction in $\mathrm{CH}_{4}$}

Although genetic selection is possible, the potential magnitude of selection for MY is unknown. Pinares-Patiño et al. (2013a) report a difference of $8 \%$ in MY between sheep after 
Pickering, Oddy, Basarab, Cammack, Hayes, Hegarty, Lassen, McEwan, Miller, Pinares-Patiño and de Haas

Table 2 Summary of the main methodologies for individual methane measurements

\begin{tabular}{lllll}
\hline \hline Method & Robust & Intrusive & Cost & Throughput \\
\hline Respiration chamber & Yes & Yes & High & Low \\
Short-term accumulation chamber & Yes & Yes, but easily managed with grazing animals & Low & High \\
Greenfeed monitors & $?$ & Moderately, requires modified grazing pattern & High & Moderate \\
$\mathrm{SF}_{6}$ & $?$ & Yes for sampling, less so for grazing & High & Moderate \\
\hline \hline
\end{tabular}

one generation of selection for and against MY. The extent to which variation in MY can be exploited, depends on the stability of the underpinning relationships with production traits. The best way to incorporate this is with a selection index that includes traits related to production, functional traits and environmental impact. This will result in a slower response to selection for all traits, but in a good overall response to the overall breeding goal. The mechanisms that contribute to genetic variation in MY of individual animals may include: reduced fermentation of organic matter in the rumen (due to shorter retention time of digesta; PinaresPatiño et al., 2011 and smaller rumen volume; Goopy et al., 2014), instability of fermentation (natural occurring defaunation; Faichney and Graham, 1996), different microbial populations in the rumen and potentially reductive acetogenesis (inferred from Faichney and Graham, 1996). The extent to which these combine to produce natural variation in MY is unknown, but data from measurement of MY in sheep using RCs suggest that the coefficient of variation is $10.3 \%$ (Pinares-Patiño et al., 2013a) and for cattle 14\% (Donoghue et al., 2013). It would not be unreasonable to anticipate a response to long term selection to exceed 2 standard deviations from the mean, suggesting that a reduction of up to $25 \%$ in MY may be feasible through selection of livestock for low MY. Combined with potential reduction in $\mathrm{CH}_{4}$ emissions due to selection for low $\mathrm{RFI}$, this suggests that a reduction in $\mathrm{CH}_{4}$ emissions of $40 \%$ to $45 \%$ may be possible through selection of individual animals on components that directly affect $\mathrm{CH}_{4}$ production. Differences in feed intake of $1.17 \mathrm{~kg} /$ day between beef cattle selected for and against RFI were observed after 2.4 generations, equivalent to a difference of $18 \mathrm{~g} \mathrm{CH}_{4} /$ day around a mean $180 \mathrm{~g} \mathrm{CH}_{4} /$ day or a $10 \%$ difference (Hegarty et al., 2007). It remains to be seen if this is independent of productive traits, although in practice selection for reduced feed intake and $\mathrm{CH}_{4}$ emissions will be conducted using an index that includes production traits.

\section{Expectations of methods for measuring $\mathrm{CH}_{4}$}

The key requirements of a methodology for measurement of $\mathrm{CH}_{4}$ production and MY of individual animals for genetic selection are, first, the methodology must provide a reliable measure of the true $\mathrm{CH}_{4}$ emission by the individual for the period of measurement and suitable for the production system under target. This requires that the recovery of $\mathrm{CH}_{4}$ emissions by the measurement procedure be consistent and preferably $100 \%$. The RC, PACs, GEMs and $\mathrm{SF}_{6}$ all potentially meet these criteria (Table 2). Methods where recovery is $<100 \%$ might be useful if they show consistent recovery and capture diurnal variance in emissions rate. These include GEMs and sniffers which permit losses of $\mathrm{CH}_{4}$ between animal and sensor.

Second, the period of measurement (of $\mathrm{CH}_{4}$ and for MY, feed intake) and number of measurement periods should be sufficient to reliably rank sires for estimation of breeding values. In practice, this means multiple measures per animal. The optimal period and number of measurements will be determined by the pedigree structure of the data and the purpose of research. The repeatability of $\mathrm{CH}_{4}$ measurements in PACs is only slightly less than in RCs (Table 2; Pinares-Patiño et al., 2013a). There is limited data to reliably estimate repeatability of $\mathrm{CH}_{4}$ emissions using $\mathrm{SF}_{6}$ and GEMs (Table 1), but it is anticipated that it would be less than in RCs. Having more progeny per sire will increase the accuracy of the estimate of sire EBVs and having more sires will improve the accuracy of the initial estimates of heritability. Finally, the measurement must be robust over time, as low cost as possible, not unduly influence animal behaviour and permit a high rate of data capture with low labour requirements. Ideally it should replicate the normal production system as far as possible.

\section{Conclusions}

There is potential for adopting genetic selection and in the future genomic selection, for reduced $\mathrm{CH}_{4}$ emissions in ruminants. From this review it has been observed that direct measurement of $\mathrm{CH}_{4}$ emissions from $\mathrm{RC}, \mathrm{SF}_{6}$ or PAC has proven underlying animal genetic variability. Subsequently, indirect indicators were explored through genetic correlations with $\mathrm{CH}_{4}$ trait. It can be concluded that indirect and genomic selection might be possible options for near future selection. $\mathrm{CH}_{4}$ emissions are a heritable and repeatable trait. $\mathrm{CH}_{4}$ emissions are strongly related to feed intake both in the short term (minutes to several hours) and over the medium term (days). When measured over the medium term, MY is a heritable and repeatable trait albeit with less genetic variation than for total $\mathrm{CH}_{4}$ emission (g/day). $\mathrm{CH}_{4}$ emissions of individual animals are moderately repeatable across diets, and across feeding levels, when measured in RCs. Repeatability is less when short-term measurements are 
used, possibly due to variation in time and amount of ingested feed before the measurement. However, repeated measurements add value; it is preferable the measures be separated by at least 3 to 14 days. This needs to be investigated further. Given the above issue can be resolved, short-term (over minutes to hours) measurements of $\mathrm{CH}_{4}$ emissions show promise. Finally, we believe that for shortterm measurements to be useful for genetic evaluation, a number (between 3 and 20) of measurements will be required over an extended period of time (weeks to months).

There are opportunities for using short-term measurements in standardised feeding situations such as breath 'sniffers' attached to milking parlours or total mixed ration feeding bins, to measure $\mathrm{CH}_{4}$. We anticipate these are also subject to the caveats above about the use of short-term measurements. The measurement 'protocol' (i.e. how the animal and its feeding behaviour are managed before measurement) is more important than the technology used to make the $\mathrm{CH}_{4}$ measurement. While there is evidence that correlated and predictor traits exist for $\mathrm{CH}_{4}$ emissions the current level of knowledge is insufficient to recommend their use in genetic selection to reduce $\mathrm{CH}_{4}$ emissions. Genomic selection has the potential to reduce $\mathrm{CH}_{4}$ emissions and MY, however, measurements on thousands of individuals will be required. This includes the need to combined resources across countries in an international effort, emphasising the need for acknowledging the impact of the animal and production system on measurement of the $\mathrm{CH}_{4}$ trait during design of experiments. The 'size of the prize' when combining lower MY with selection for low RFI may result in a reduction in $\mathrm{CH}_{4}$ emissions of $40 \%$ to $45 \%$ and may be possible through selection of individual animals on components that directly affect $\mathrm{CH}_{4}$ production.

In summary we consider genetic and genomic selection offers a significant opportunity to reduce $\mathrm{CH}_{4}$ emissions from ruminants. However attention needs to be directed to a number of issues if short-term low-cost measurements are to be implemented in industry.

\section{Acknowledgements}

This review is partly based on the development of knowledge reached within the networks of COST Action FA1302 'Largescale methane measurements on individual ruminants for genetic evaluations' and the Animal Selection, Genetics and Genomics Network of the Livestock Research Group of the Global Research Alliance on agricultural greenhouse gases. The authors are grateful for the support from the European Science Foundation providing for the COST office and to all scientists contributing to the development work in this network.

\section{Supplementary material}

To view supplementary material for this article, please visit http://dx.doi.org/10.1017/S1751731115000968

\section{References}

Bickell SL, Robinson DL, Toovey AF, Goopy JP, Hegarty RS, Revell DK and Vercoe PE 2011. Four week repeatability of daily and one hour methane production of mature merino wethers fed ad libitum. Proceedings of the Association for the Advancement of Animal Breeding and Genetics, 19 to 21 July 2011, Perth, Western Australia, Australia, pp. 415-418.

Blaxter KL 1962. The energy metabolism of ruminants. Academic Press, London, UK.

Capper JL 2011. The environmental impact of beef production in the United States; 1977 compared with 2007. Journal of Animal Science 89, 4249-4261.

Capper JL, Cady RA and Bauman DE 2009. The environmental impact of dairy production: 1944 compared with 2007. Journal of Animal Science 87, 2160-2167. Calus MPL, De Haas Y, Pszczola M and Veerkamp RF 2013. Predicted accuracy of and response to genomic selection for new traits in dairy cattle. Animal 7, 183-191. Chagunda MGG, Ross D, Rooke J, Yan T, Douglas JL, Poret L, McEwan NR, Teeranavattanakul $P$ and Roberts DJ 2013. Measurement of enteric methane from ruminants using a hand-held laser methane detector. Acta Agriculturæ Scandinavica Section A: Animal Science 63, 68-75.

Cottle DJ, Nolan JV and Wiedemann SG 2011. Ruminant enteric methane mitigation: a review. Animal Production Science 51, 491-514.

Daetwyler HD, Villanueva B and Woolliams JA 2008. Accuracy of predicting the genetic risk of disease using a genome-wide approach. PLoS One 3 (10), e3395.

de Haas Y, Windig JJ, Calus MPL, Dijkstra J, de Haan M, Bannink A and Veerkamp RF 2011. Genetic parameters for predicted methane production and potential for reducing enteric emissions through genomic selection. Journal of Dairy Science 94, 6122-6134.

Dehareng F, Delfosse C, Froidmont E, Soyeurt H, Martin C, Gengler N, Vanlierde A and Dardenne P 2012. Potential use of milk mid-infrared spectra to predict individual methane emission of dairy cows. Animal 6, 1694-1701.

Deighton MH, Williams SRO, Eckard RJ, Boland TM and Moate PJ 2013. High concordance of $\mathrm{CH} 4$ emission is possible between the $\mathrm{SF}_{6}$ tracer and respiration chamber techniques. Advances in Animal Biosciences 4, 411.

Donoghue KA, Herd RM, Bird SH, Arthur PF and Hegarty RF 2013. Preliminary genetic parameters for methane production in Australian beef cattle. Proceedings of the Association for the Advancement of Animal Breeding and Genetics, 20 to 23 October 2013, Napier, New Zealand, pp. 290-293.

Dougherty RW, Allison MJ and Mullenax CH 1964. Physiological disposition of $\mathrm{C}^{14}$-labeled rumen gases in sheep and goats. American Journal of Physiology 207, 1181-1188.

FAOSTAT 2013. Emissions - Agriculture - enteric fermentation. Retrieved March 18, 2013, from http://faostat3.fao.org/home/

Faichney GJ and Graham NM 1996. Reduced emissions associated with unstable rumen fermentation in sheep. Proceedings of the Nutrition Society of Australia 20, 120-123.

Forster P, Ramaswamy V, Artaxo P, Berntsen T, Betts R, Fahey DW, Haywood J, Lean J, Lowe DC, Myhre G, Nganga J, Prinn R, Raga G, Schulz M and Van Dorland $R$ 2007. Changes in atmospheric constituents and in radiative forcing. In Climate Change 2007: the physical science basis. Contribution of Working Group I to the Fourth Assessment Report of the Intergovernmental Panel on Climate Change (ed. S Solomon, D Qin, M Manning, Z Chen, M Marquis, KB Averyt, M Tignor and HL Miller), pp. 129-234. Cambridge University Press, Cambridge, United Kingdom and New York, NY, USA.

Gardiner TD and Coleman MD 2013. Metrological assessment of the absolute accuracy of methane emission measurements from livestock chambers in the UK. Advances in Animal Biosciences 4, 480.

Garnsworthy PC, Craigon J, Hernandez-Medrano JH and Saunders H 2012. On-farm methane measurements during milking correlate with total methane production by individual dairy cows. Journal of Dairy Science 95, 3166-3180.

Gerber PJ, Steinfeld H, Henderson B, Mottet A, Opio C, Dijkman J, Falcucci A and Tempio $G$ 2013. Tackling climate change through livestock - a global assessment of emissions and mitigation opportunities. Food and Agriculture Organization of the United Nations. FAO, Rome.

Goddard ME 2008. Genomic selection: prediction of accuracy and maximisation of long term response. Genetica 136, 245-257.

Goopy JP, Woodgate R, Donaldson A, Robinson DL and Hegarty RS 2011. Validation of a short term methane measurement using portable static chambers to estimate methane production in sheep. Animal Feed Science and Technology 166-167, 219-226. 
Pickering, Oddy, Basarab, Cammack, Hayes, Hegarty, Lassen, McEwan, Miller, Pinares-Patiño and de Haas

Goopy JP, Donaldson A, Hegarty R, Vercoe PE, Haynes F, Barnett M and Oddy VH 2014. Low-methane yield sheep have smaller rumens and shorter rumen retention time. British Journal of Nutrition 111, 578-585.

Gregorini P 2012. Diurnal grazing pattern: its physiological basis and strategic management. Animal Production Science 52, 416-430.

Hayes BJ, Visscher PM and Goddard ME 2009. Increased accuracy of artificial selection by using the realized relationship matrix. Genetics Research 91, 47-60.

Hayes BJ, Lewin HA and Goddard ME 2013. The future of livestock breeding: genomic selection for efficiency, reduced emissions intensity, and adaptation. Trends in Genetics 29, 206-214.

Hegarty RS 2004. Genetic diversity in function and microbial metabolism of the rumen. Australian Journal of Experimental Agricultural 44, 1-9.

Hegarty RS 2013. Applicability of short term emission measurements for on-farm quantification of enteric methane. Animal 7 (s2), 401-408

Hegarty RS, Goopy JP, Herd RM and McCorkell B 2007. Cattle selected for lower residual feed intake have reduced daily methane production. Journal of Animal Science 85, 1479-1486.

Herd RM, Bird SH, Donoghue KA, Arthur PF and Hegarty RS 2013. Phenotypic associations between methane production traits, volatile fatty acids and animal breeding traits. Proceedings of the Association for the Advancement of Animal Breeding and Genetics, 20 to 23 October 2013, Napier, New Zealand, pp. 286-289.

Heywood LH and Wood KW 1985. Thoracic oesophageal motor activity during eructation in sheep. Quarterly Journal of Experimental Physiology 70, 603-613. Hoernicke H, Williams WF, Waldo DR and Flatt WP 1965. Composition and absorption of rumen gases and their importance for the accuracy of respiration trials with tracheostomized ruminants. In Energy metabolism (ed. KL Blaxter), pp. 165-178. Academic Press, London, UK.

Hofmeyr HS, Slabbert N and Pienaar JP 1984. Partitioning of methane production between ruminal and hindgut fermentation sites in sheep. Candian Journal of Animal Science 64, 171-172.

Hristov AN, Oh J, Firkins JL, Dijkstra J, Kebreab E, Waghorn G, Makkar HPS Adesogan AT, Yang W, Lee C, Gerber PJ, Henderson B and Tricario JM 2013 a. Mitigation of methane and nitrous oxide emissions from animal operations: 1. A review of enteric methane mitigation options. Journal of Animal Science 91, 5045-5069.

Hristov AN, Ott T, Tricario JM, Rotz A, Waghorn G, Adesogan AT, Dijkstra J, Montes F, Oh J, Kebreab E, Oosting SJ, Gerber PJ, Henderson B, Makkar HPS and Firkins JL 2013b. Mitigation of methane and nitrous oxide emissions from animal operations: 3. A review of animal management mitigation options. Journal of Animal Science 91, 5095-5113.

Intergovernmental Panel on Climate Change 2006. IPCC Guidelines for National Greenhouse Gas Inventories, volume 4. Agriculture, forestry and other land use. Retrieved November 15, 2013, from http://www.ipcc-nggip.iges.or.jp/public/ 2006gl/

Johnson KA and Johnson DE 1995. Methane emissions from cattle. Journal of Animal Science 73, 2483-2492.

Knight TW, Molano G, Clark H and Cavanagh A 2008. Methane emissions from weaned lambs measured at 13,17, 25 and 35 weeks of age compared with mature ewes consuming a fresh forage diet. Animal Production Science 48, 240-243.

Lassen J, Løvendahl P and Madsen J 2012. Accuracy of non-invasive breath methane measurements using Fourier transformed infrared methods on individual cows. Journal of Dairy Science 95, 890-898.

Lassey KR, Ulyatt MJ, Martin RJ, Walker CF and Shelton ID 1997. Methane emissions measured directly from grazing livestock in New Zealand. Atmospheric Environment 31, 2905-2914.

Martin C, Morgavi DP and Doreau M 2010. Methane mitigation in ruminants: from microbe to the farm scale. Animal 4, 351-365.

Mathers JC and Walters DE 1982. Variation in methane production by sheep fed every two hours. Journal of Agricultural Science 98, 633-638.

McCauley EH and Dziuk HE 1965. Correlation of motility and gas collection from goat rumen. American Journal of Physiology 209, 1152-1154.

McEwan JC, Hickey SM, Young E, Dodds KG, McLean S, Molano G, Sandoval E, Kjestrup H, Hunt C and Pinares-Patiño C 2012. Heritability estimates for hourly measures of methane emissions. In 33rd Conference of the International Society for Animal Genetics, 15 to 20 July 2012, Cairns, Australia, P4021.

McGinn SM, Beauchemin KA, Iwaasa AD and McAllister TA 2006. Assessment of the sulfur hexafluoride (SF6) tracer technique for measuring enteric methane emissions from cattle. Journal of Environmental Quality 35, 1686-1691.

McPhee MJ and Hegarty RS 2008. Predicting the metabolizbale energy intake of ruminants using digestibility, ruminal methane production and fermentation data. Journal of Agricultural Science 146, 643-654.

Meuwissen T, Hayes B and Goddard M 2013. Accelerating improvement of livestock with genomic selection. Annual Review of Animal Biosciences 1, 221-237.

Michal JJ, White RR, Guerouali A and Johnson KA 2013. An examination of the ranking of methane emissions measurements from growing beef heifers fed different forage diets over time. Advances in Animal Biosciences 4, 536.

Mortola JP and Lanthier C 2005. Breathing frequency in ruminants: a comparative analysis with non-ruminant mammals. Respiratory Physiology and Neurobiology 145, 265-277.

Münger A and Kreuzer M 2008. Absence of persistent methane emission differences in three breeds of dairy cows. Animal Production Science 48, 77-82.

Murray PJ, Gill E, Balsdon SL and Jarvis SC 2001. A comparison of methane emissions from sheep grazing pastures with differing management intensities. Nutrient Cycling Agroecosystems 60, 93-97.

Murray RM, Byrant AM and Leng RA 1976. Rates of production of methane in the rumen and large intestine of sheep. British Journal of Nutrition 36, 1-14.

Negussie E, Liinamo AE, Mäntysaari P, Mäntysaari EA and Lidauer M 2012. Between and within-individual variation in methane output measurements in dairy cows. In Proceedings of the 63rd Annual meeting of the European Association of Animal Production, 27 to 31 August 2012, Bratislava, Slovakia, p. 170.

Nolan JV, Hegarty RS, Hegarty J, Godwin IR and Woodgate R 2010. Effects of dietary nitrate on fermentation, methane production and digesta kinetics in sheep. Animal Production Science 50, 801-806.

Piccione G, Caola G and Mortola JP 2004. Day/night pattern of arterial blood gases in the cow. Respiratory Physiology and Neurobiology 140, 33-41.

Pinares-Patiño CS, McEwan JC, Dodds KG, Cárdenas EA, Hegarty RS, Koolaard JP and Clark H 2011. Repeatability of methane emissions from sheep. Animal Feed Science and Technology 166-167, 210-218.

Pinares-Patiño CS, Hickey SM, Young EA, Dodds KG, MacLean S, Molano G, Sandoval E, Kjestrup H, Harland R, Pickering NK and McEwan JC 2013a. Heritability estimates of methane emissions from sheep. Animal 7, 316-321.

Pinares-Patiño CS, Kjestrup H, MacLean S, Sandoval E, Molano G, Harland R, Hickey S, Young E, Dodds K, Knowler K, Pickering N and McEwan J 2013b. Methane emission from sheep is related to concentrations of rumen volatile fatty acids. Proceedings of the 4th International Symposium on Energy Protein Metabolism and Nutrition, 9 to 12 Septemer 2013, Sacramento, California, USA. Robinson DL 2009. Improving the accuracy of selecting animals for reduced methane emissions. Proceedings of the Association for the Advancement of Animal Breeding and Genetics, 28 September to 1 October 2009, Barossa Valley, South Australia, Australia, pp. 644-647.

Robinson D, Goopy J, Hegarty R and Vercoe P 2010. Repeatability, animal and sire variation in 1-hr methane emissions and relationships with rumen volatile fatty acid concentrations. Proceedings of the 9th World Congress on Genetics Applied to Livestock Production, 1 to 6 August 2010, Leizig, Germany, p. 712

Smith P, Martino D, Cai Z, Gwary D, Janzen H, Kumar P, McCarl B, Ogle S, O'Mara F, Rice C, Scholes B and Sirotenko 0 2007. Agriculture. In Climate Change 2007: Mitigation. Contribution of Working Group III to the Fourth Assessment Report of the Intergovernmental Panel on Climate Change (ed. B Metz, OR Davidson, PR Bosch, R Dave and LA Meyer), pp. 497-540. Cambridge University Press, Cambridge, UK.

Tubiello FN, Salvatore M, Rossi S, Ferrara A, Fitton N and Smith P 2013. The FAOSTAT database of greenhouse gas emissions from agriculture. Environmental Research Letters 8, 10pp.

Wall E, Simm G and Moran D 2010. Developing breeding schemes to assist mitigation of greenhouse gas emissions. Animal 4, 366-376. 